\title{
THE EFFECTS OF COMPOUND A (11-DEHYDROCORTIĆOSTERONE) AND COMPOUND F (17-HYDROXYCORTICOSTERONE) ON TOTAL BODY FAT ${ }^{1}$
}

\author{
BY LAURENCE H. KYLE, RICHARD J. MEYER, ${ }^{2}$ MARCUS SCHAAF, ${ }^{3}$ AND \\ EDWARD J. WERDEIN \\ (From the Department of Medicine, Georgetown University Medical Center, Washington, D. C.)
}

(Submitted for publication April 4, 1956; accepted May 17, 1956)

Speculation regarding the influence of adrenal cortical hormones on body fat has engendered little experimental scrutiny, a deficiency which undoubtedly stems from the difficulties in performing in vivo measurement of the fat content of the body. Fundamental observations of Behnke, Feen, and Welham (1) on the relationship of body fat to body specific gravity suggested the possibility of utilizing serial measurements of body specific gravity for the evaluation of hormonally induced changes in body composition (2). Measurement of specific gravity by underwater weighing has been used in this laboratory to study the effects of $\mathrm{ACTH}$, Compound E, Compound F and, to very limited degree, of Compound A on body fat (3). Because of an apparent increase in fat during treatment with Compound F, and because Compound $A$ has been implicated as a fat-affecting hormone, more complete study of these hormones was believed desirable.

\section{METHODS AND MATERIALS}

The subject of this study was a 37-year-old white man with chronic dermatitis. He was hospitalized on the metabolic ward for two periods of about 4 months each under conditions of constant activity. The first study was performed when he was moderately depleted and the second study was conducted 15 months later after considerable repletion of fat and protein had been accomplished.

Body weight was measured each morning before breakfast, following completion of the 24-hour urine collection. The patient was given a constant diet containing 2200 calories, 90 grams of protein, 105 grams of fat and

1 This study was supported by the William Wade Hinshaw Fund and by a contract between Georgetown University and the Office of Naval Research. Reproduction in whole or in part is permitted for any purpose of the United States Government.

2 Formerly a Research Fellow of the National Institutes of Health.

${ }^{3}$ Formerly the William Wade Hinshaw Cancer Research Fellow.
225 grams of carbohydrate. Intake of sodium and potassium was calculated from standard food tables, allowance being made for sodium given as sodium thiocyanate. Rejected portions of the diet were given with the following meal; unfinished portions of the evening meal were given before sleep. The subject was permitted to leave the hospital for a few hours once weekly; there occurred only one major and a single minor violation of the dietary routine at these times.

Blood for laboratory analysis was drawn in relatively constant amounts and at regular intervals to provide uniform nitrogen loss by this route. Aliquots of 2-day pooled urine collections were refrigerated until analysis. Urinary nitrogen was measured by a micro-Kjeldahl technique. Nitrogen loss from blood sampling and in stools was estimated to total $1.6 \mathrm{gm}$. per day. Urinary sodium and potassium were measured by an internal standard flame photometer. Water balance was estimated from the difference between urine output and fluid intake, consisting of the liquid portion of the diet and measured amounts of distilled water.

Body specific gravity was obtained by the method of underwater weighing devised by Behnke, Feen, and Welham (1) as described from these laboratories $(2,3)$ :

$$
\text { Sp. Gr. }=\frac{\text { Weight in air }}{\text { Weight in air - true weight in water }}
$$

Submerged weight was measured at a water temperature of 32 to $34^{\circ} \mathrm{C}$. and corrected for residual lung volume, measured by the helium dilution technique of Willmon and Behnke (4). In correcting for residual lung volume, density of the water was ignored because of the minor error involved as well as the fact that data were obtained from successive measurements of the subject under the same standard conditions. At the time of each measurement underwater weight was obtained during both deep inspiration and full expiration. The difference was checked against measured vital capacity to insure expiration to a relatively constant volume of residual air at each weighing.

Total body fat was estimated by substitution in the Rathbun-Pace equation (5), formulated on the assumption that the specific gravity of fat is 0.918 :

$$
\% \text { Fat }=100\left(\frac{5.548}{\text { sp. gr. }}-5.044\right)
$$

Total body water was calculated from specific gravity by substitution in the equation derived by Osserman, 


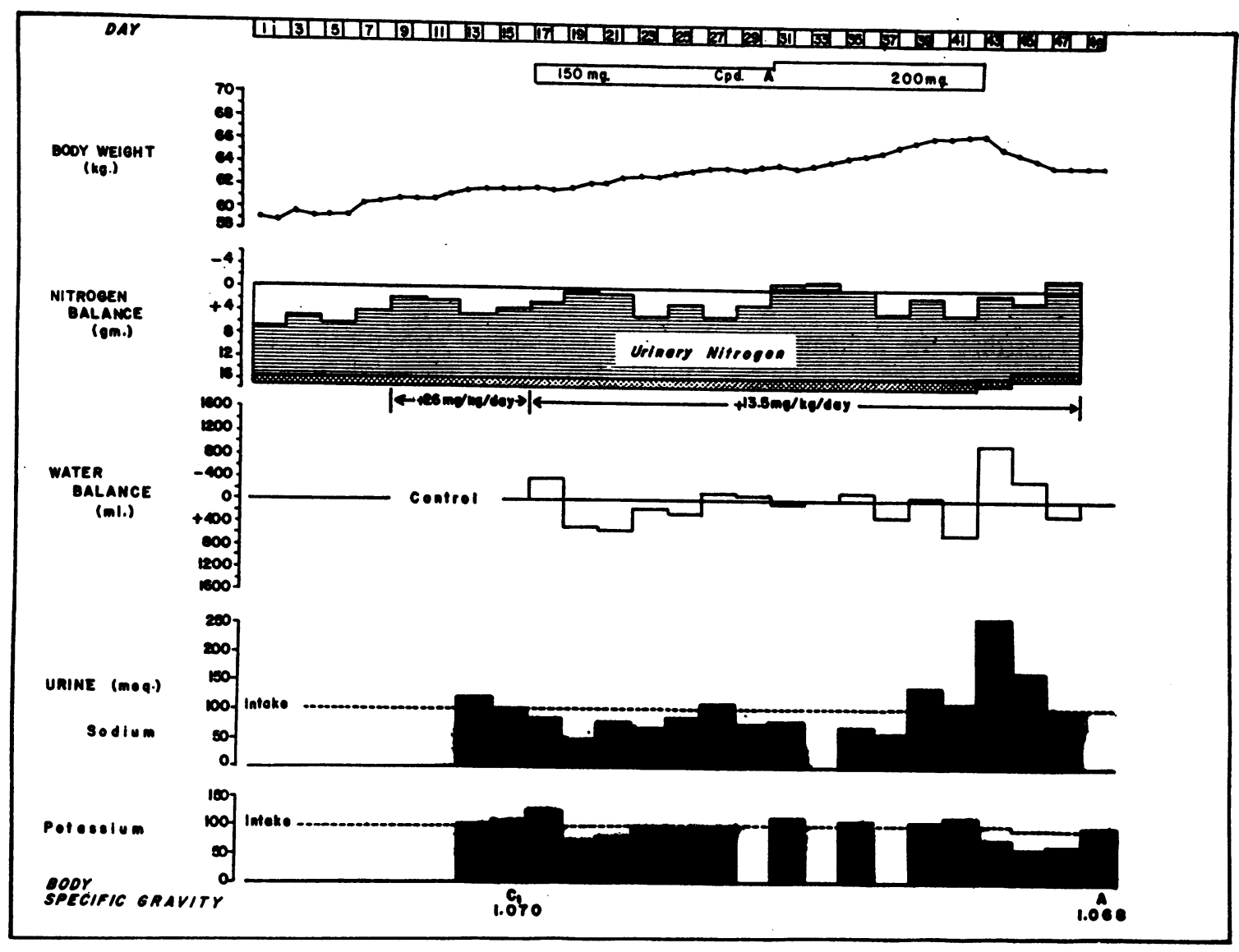

Fig. 1. Metabolic Changes During Treatment With Compound A

Pitts, Welham, and Behnke (6) :

$$
\% \text { Water }=100\left(4.340-\frac{3.983}{\text { sp. gr. }}\right)
$$

Fat free solids were assumed to comprise the difference between body weight and the sum of the weights of fat and water.

Because estimation of body composition by the specific gravity method is accurate only in the normally hydrated subject greatest reliance was placed on those measurements obtained when there existed the least amount of compartmental distortion. Parallel measurements of body water compartments were made by volume distribution techniques, particularly during the second study. Total body water (TBW) was estimated by measurement of antipyrine space, using the technique of Brodie, Axelrod, Soberman, and Levy (7) and by $\mathrm{D}_{2} \mathrm{O}$ space, using the method of Broida, Morowitz, and Selgin (8). The extracellular fluid compartment (ECF) was assumed to be 70 per cent of the thiocyanate space, measured as described by Eder (9). Intracellular fluid (ICF) was assumed to be the difference between TBW and ECF. In all calculations involving total body water the values for antipyrine space were used because these checked much more closely with estimation of total body water by the specific gravity method than did the $\mathrm{D}_{2} \mathrm{O}$ space.

Measurement of these fluid compartments permitted two methods of correction of hydration abnormality in estimating fat from body specific gravity. One consisted of substitution of the value for body density and that for antipyrine space in the equation derived by Siri (10):

$$
\% \text { Fat }=225(1 / D)-0.76 \% \text { water }-150 .
$$

Proper correction was made for the density of water (0.994 at the temperature used to obtain submerged weight) in conversion of specific gravity to density. The other correction applied was that of variation in ECF (corrected thiocyanate space) in the density equation: $\mathrm{D}=\frac{\text { Mass. }}{\text { Volumé }}$, as suggested by Keys and Brožek (11), correcting for the density of water on each occasion.

Calculation of change in body fat was also conducted by application of volume distribution techniques. The concept of the fat free body advanced by McCance and Widdowson (12) was utilized as follows:

Fat $=$ weight $-\mathrm{T}-\left(\frac{\mathrm{A}-\mathrm{T}}{0.67}\right)-0.075\left(\mathrm{~T}+\frac{\mathrm{A}-\mathrm{T}}{0.67}\right)$ 


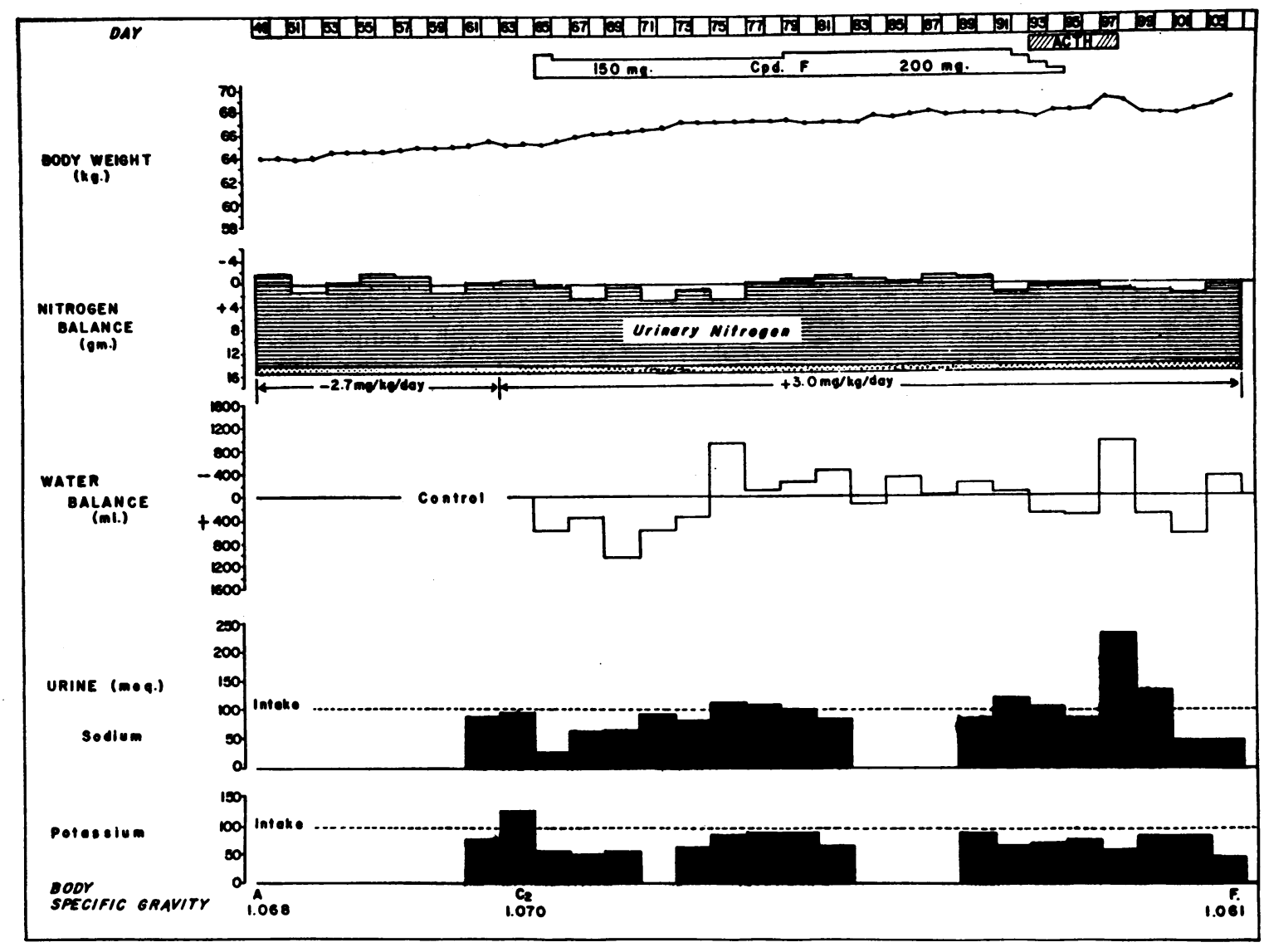

Fig. 2. Metabolic Changes During Treatment With Compound F

where $\mathrm{T}$ is corrected thiocyanate space and $\mathrm{A}$ is antipyrine space. Change in fat was also determined from the difference between total weight change and the sum of the changes in antipyrine space and nitrogen balance $\times 6.25(13)$.

Density of tissue gained was calculated from the ratio of change in the subject's weight to change in his volume.

Oxygen consumption was measured under fasting conditions by a closed circuit clinical apparatus. The average of two determinations was used in each instance. Urine calcium was measured by the method of Clark and Collip (14).

Compound $\mathrm{A}$ acetate was given intramuscularly in 3 to 4 divided doses each day. Compound $F$ was administered orally every 6 to 8 hours. 4

\section{RESULTS}

The metabolic changes which accompanied treatment with Compound A are shown in Figure 1. Nitrogen balance, which was very positive during

4 These drugs were obtained through the generosity of Dr. Augustus Gibson of Merck \& Co. the control period, became less positive, but only temporarily, when Compound $\mathrm{A}$ was started and when the dose was increased. Retention of both water and sodium occurred at these times. Body weight, which was increasing during the control period, rose more sharply during therapy but fell off quickly with the salt and water diuresis which followed cessation of treatment. Body specific gravity was 1.070 at the beginning of treatment -1.068 after the post-treatment diuresis.

The changes with Compound $\mathrm{F}$ are depicted in Figure 2. During the control period the patient was in approximate nitrogen balance and very little change resulted from the administration of Compound F. Retention of water and sodium was of similar magnitude to that noted with Compound A therapy. There was acceleration of weight gain, particularly when ACTH was given briefly at the termination of treatment. Cessation of all therapy was again followed by diuresis of salt and water 
with loss of weight. Body specific gravity, which was 1.070 at the end of the second control period, fell to 1.061 after the administration of Compound F.

Figure 3 summarizes the changes in body composition during the entire study. Here again may be seen the weight gain during the control period, more rapid gain with Compound $\mathrm{A}$ and decrease in weight when therapy was discontinued. Body specific gravity decreased slightly during treatment and rose after the post-treatment diuresis. During the second control period there was steady increase in weight and slight rise in specific gravity to the previous control value. When Compound $\mathrm{F}$ was given there occurred more rapid weight gain and a pronounced lowering of specific gravity. This fell to 1.056 with the increased water retention accompanying ACTH therapy and rose moderately after treatment was discontinued.

It may be recalled that this technique of measurement is considered most valid when the major body constituents are in relatively normal proportions, particularly when there is no abnormal hydration. Consequently detailed analysis was made of four specific gravity determinations, selected at times when hydration abnormality should have been absent or minimal: $\mathrm{C}_{1}$-prior to treatment with Compound A; A-following the post-treatment diuresis when body weight had stabilized; $\mathrm{C}_{2}$ - just before treatment with Compound $\mathrm{F}$ and; $\mathrm{F}$-after the diuresis which followed cessation of treatment. At $C_{1}$ specific gravity was 1.070 indicating a total fat content of $8.7 \mathrm{~kg}$. Following treatment with Compound A the specific gravity was 1.068 , representative of a total body fat value of $9.7 \mathrm{~kg}$. At the end of the second control period $\left(\mathrm{C}_{2}\right)$ body specific gravity was identical with the original control value-1.070; but after the administration of Compound $\mathrm{F}$, specific gravity fell to 1.061 indicating a $3.5 \mathrm{~kg}$. increase in body fat. These changes in body composition are shown graphically at the bottom of Figure 3. During treatment with Compound $\mathrm{A}$ there was a moderate increase in all three major body constituents but fat increased only one $\mathrm{kg}$.- - less than can be considered significant by this method of measurement. During the second control period there appeared to be a continued gain in water and fat free solids and an insignificant loss of fat. During treatment

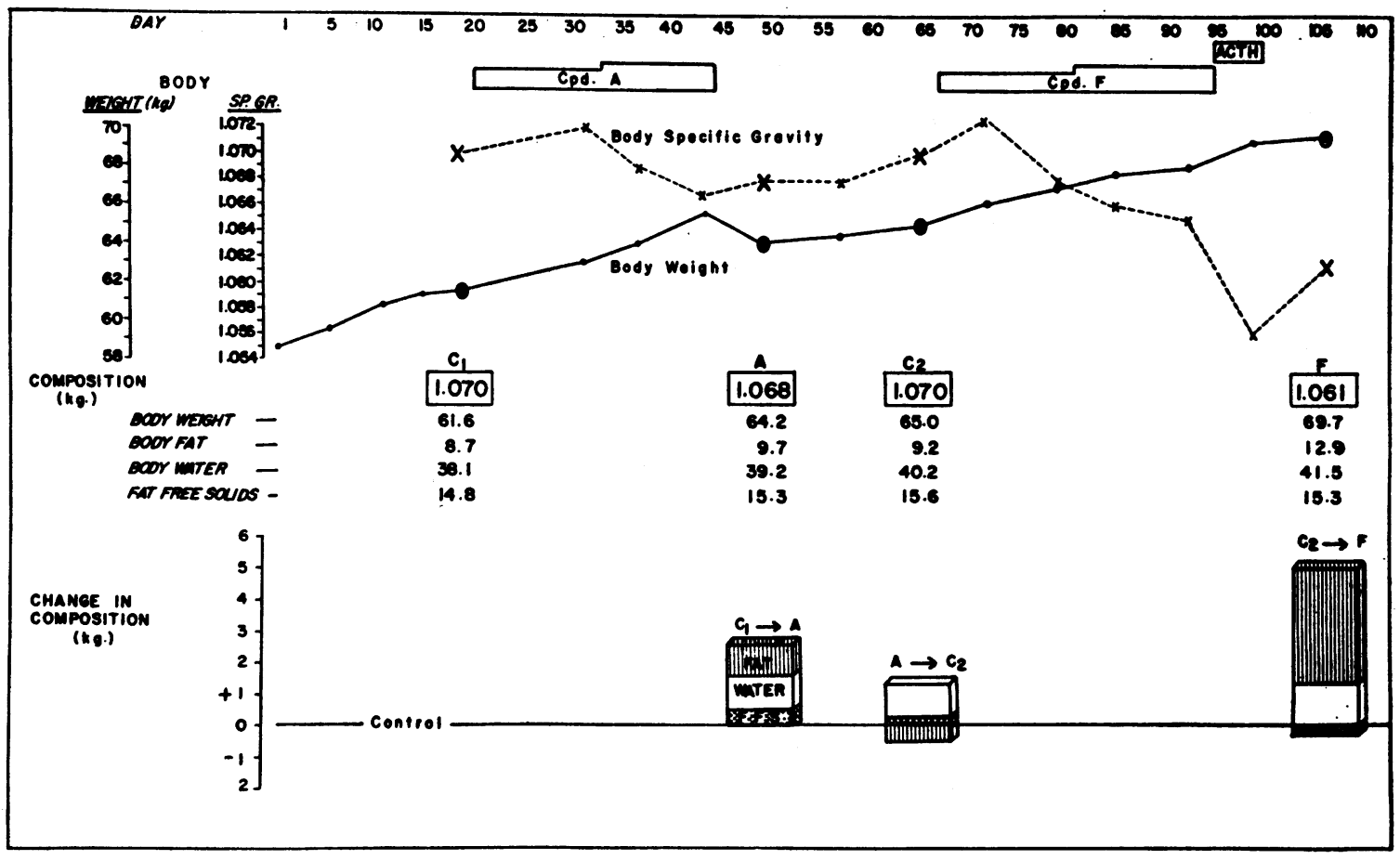

Fig. 3. Changes in Body Composition With Compounds A and F 
with Compound $F$ a significant gain in fat is apparent.

These results indicated quite clearly that Compound $\mathrm{A}$ has no particular effect on body fat. There did appear to be a significant increase in total body fat during the administration of Compound $F$. Three possible explanations for these changes were considered:

1) Fat storage occurred only because protein repletion had become complete. Lack of a significant gain in fat during the second control period, when the patient was in approximate nitrogen balance, was a strong argument against this hypothesis.

2) True acceleration of fat deposition had occurred. This possibility, while more plausible than the first, lacked a clear explanation of the mechanisms involved. Insignificant protein catabolism and use of an isocaloric diet throughout the study indicated the absence of liponeogenesis and therefore some change in energy requirements or intermediary metabolism merited consideration.

3) The gain in fat was apparent rather than real because of change in other body constituents. Loss of material of high density, such as bone mineral, in sufficient amounts to cause such a significant change in specific gravity seemed very unlikely. The possibility of abnormal fluid retention could not be entirely discounted for antipyrine space determinations made throughout the study were too variable to permit precise correction for minor hydration abnormality. On the other hand the degree of water and sodium retention during therapy with Compound $\mathrm{F}$ appeared no greater than with Compound $\mathrm{A}$, which demonstrated an insignificant effect on body specific gravity.

In view of these possibilities a second study was conducted, utilizing the same metabolic regimen but with the inclusion of multiple measurement of fluid compartments, so as to permit better correction of hydration abnormality and allow application of other methods of fat estimation. In addition, periodic measurement was made of oxygen consumption and urinary calcium excretion. During the 15 months' interval between studies the patient was maintained on $20 \mathrm{mg}$. of Compound $\mathrm{F}$ daily and encouraged to take more food so as to begin his second study at a higher level of body fat and to insure protein repletion. These objectives were accomplished, for at the beginning of the second study fat had increased to $13.5 \mathrm{~kg}$. - nearly $5 \mathrm{~kg}$. more than at the beginning of the first study-and protein stores were nearly replenished as indicated by the nitrogen balances.

Figure 4 depicts the metabolic changes and measurement of fluid compartments throughout the second study. Changes in weight were essentially the same as before, i.e., steady slow gain during each control period, more rapid gain during treatment with Compound $F$ and loss of weight after cessation of therapy. Despite the marked increase in excretion of sodium following the first course of Compound $F$ no retention of sodium occurred during treatment; in fact urinary sodium exceeded that noted in the control period. During the second course of Compound $F$ therapy there was moderate sodium retention and towards the end and after completion of treatment loss of sodium was noted. A moderate increase in nitrogen excretion accompanied the administration of larger doses of Compound $\mathrm{F}$ on one occasion but very little protein breakdown occurred during the second course of Compound F therapy. Total body water measurements gave no indication of overhydration; in fact, antipyrine and $\mathrm{D}_{2} \mathrm{O}$ spaces indicated the existence of mild dehydration after the diuresis which followed cessation of treatment.

Figure 5 demonstrates the changes in body composition estimated from specific gravity measurements during the entire second study. During the first control period there was increase in weight without significant variation in specific gravity. Administration of Compound $\mathrm{F}$ was accompanied on both occasions by more precipitous gain in weight and significant lowering of specific gravity. The fall in weight after cessation of therapy was associated with but little return of specific gravity towards control levels.

As in the first study certain periods were selected for special analysis, chosen at times when minimal hydration abnormality was likely: $\mathrm{C}_{1}$-at the beginning of study; $\mathrm{C}_{2}$-immediately before the first course of Compound $F ; F_{1}$-after the post-treatment diuresis; $\mathrm{C}_{3}$-after a second control period and $\mathrm{F}_{2}$-at the end of treatment.

The results of this study were generally in accord with the first. There occurred significant decrease in specific gravity indicative of substantial increase in fat during the administration of Compound F. Fat increased $1.9 \mathrm{~kg}$. during $F_{1}$, 


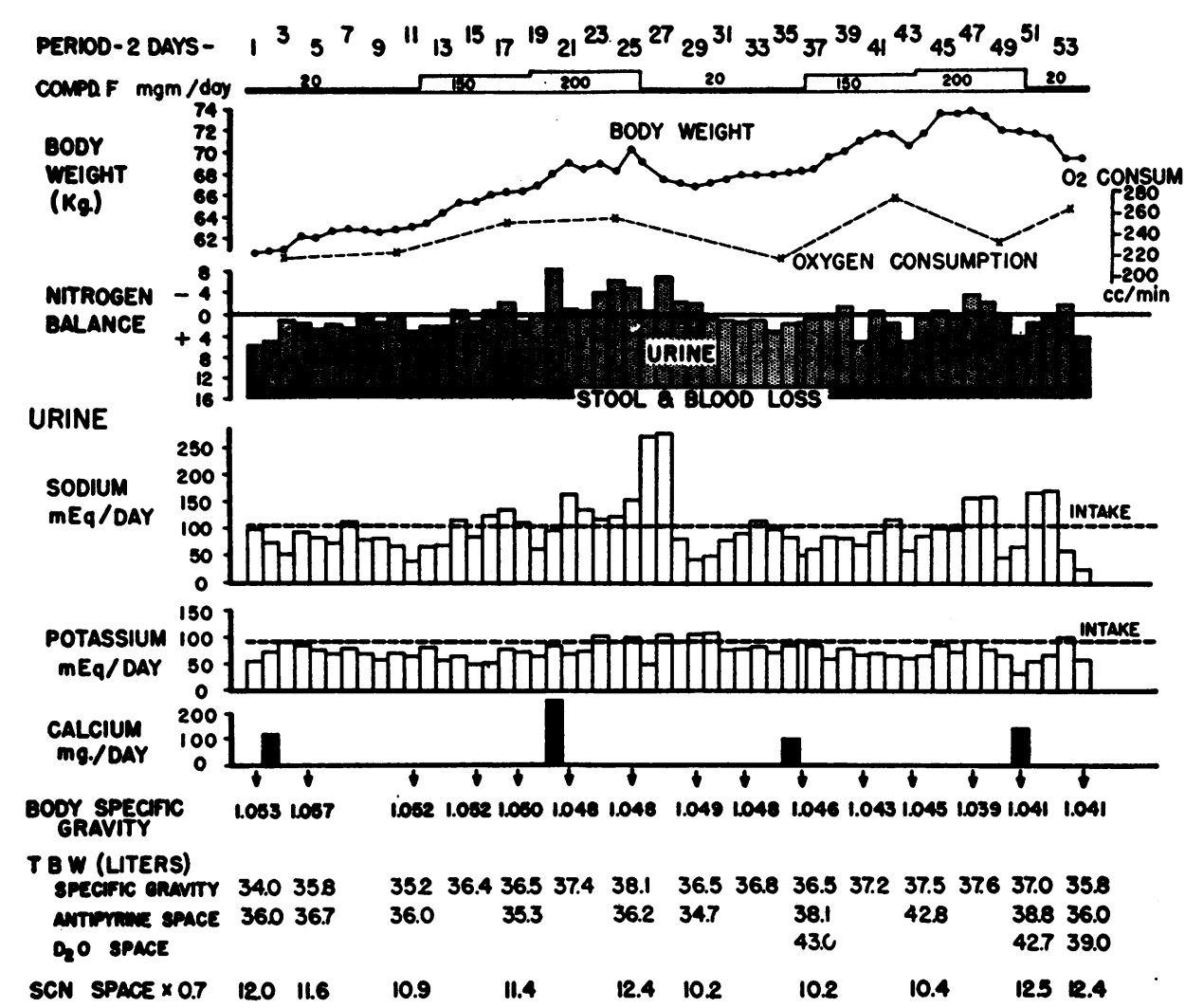

Fig. 4. Changes in Metabolic Balance and Fluid Compartments During Two Courses of Compound $F$

$2.0 \mathrm{~kg}$. during $\mathrm{F}_{2}$ and totaled $5.3 \mathrm{~kg}$. from $\mathrm{C}_{2}$ to the end of the study. There also appeared to be a continued rapid gain in body fat between the two courses of Compound $F$. While this might suggest continued lipogenic effect of Compound $F$ after cessation of treatment, it was more probably due to fluid reaccumulation. As shown by the determinations of total body water (Figure 4), there appeared to have been restoration of normal hydration during the second control period, which, because of addition of a material of low density, would indicate gain in fat. This apparent change in hydration suggests that gain of fat during treatment with Compound $F$ was even more pronounced than indicated by the fat estimates derived from these specific gravity data.

As shown in Figure 4 oxygen consumption tended to increase during treatment with Compound $F$ and excretion of calcium was insufficient to account for any measurable decrease in body specific gravity.
Table I compares the changes in body fat estimated by several different methods during the second study: (A) from specific gravity data (B) by substitution of body density and total body water (antipyrine space) in the same formula (C) by correction of the density equation for hydration abnormality as determined by change in thiocyanate space (D) by use of the technique of McCance and Widdowson (12) in estimation of the fat-free body mass and (E) by estimation of change in fat from change in body weight, change in total body water and nitrogen excretion. Use of these methods offers further support for the presence of a true increase in fat during the administration of Compound F. They also indicate that the specific gravity method of fat estimation is more uniform than those techniques which utilize only volume distribution. Although concurrent application of measurement of total body water to circumvent hydration abnormality has definite theoretical advantages it should be pointed out that the use of 


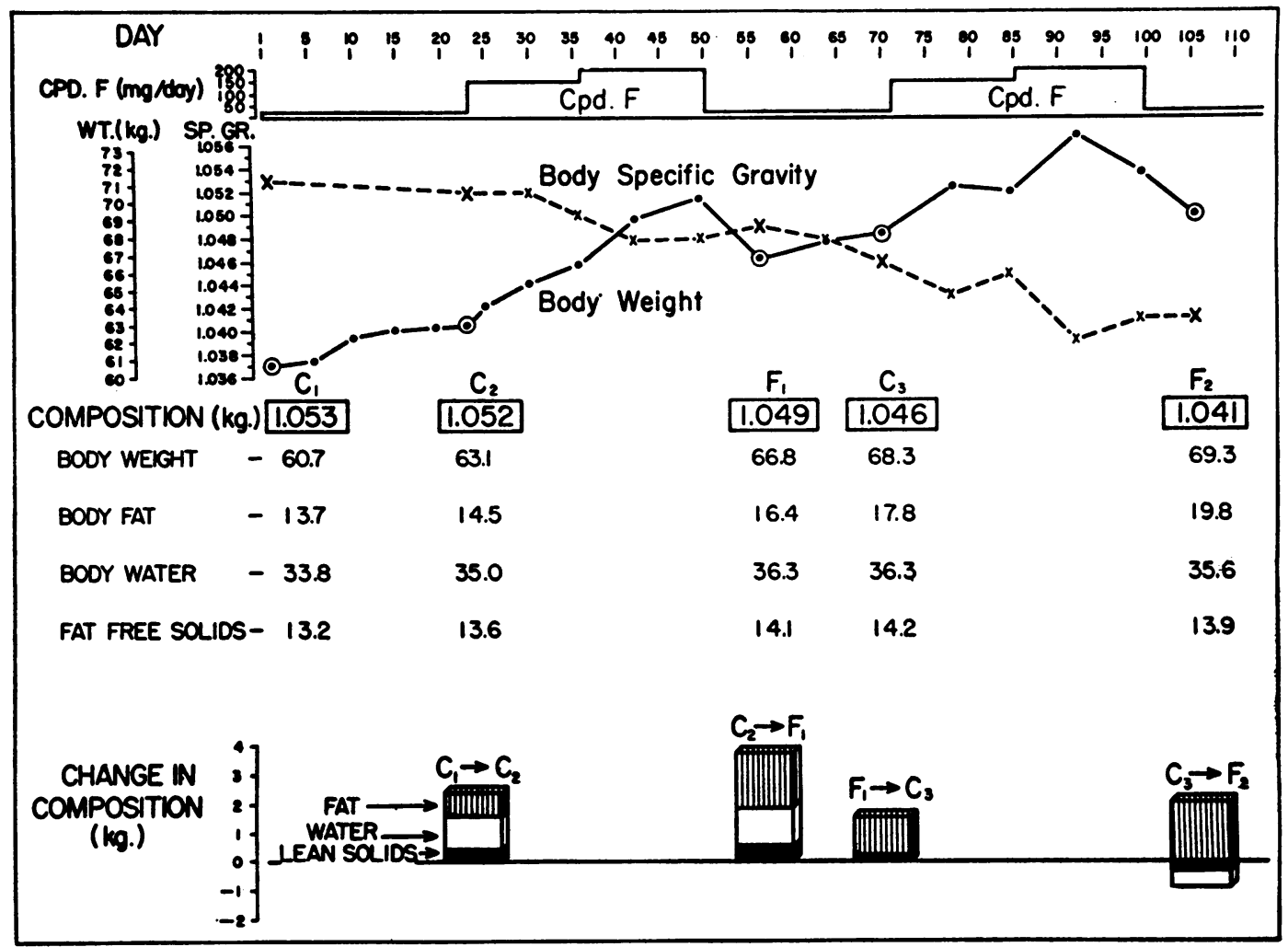

Fig. 5. Changes in Body Composition With Compound F (Second Study)

poorly reproducible techniques, such as antipyrine space, cannot always strengthen the value of a readily reproducible method such as measurement of specific gravity.

Table II summarizes the results of both studies in terms of gain in fat per day and estimation of the density of the changed tissue as determined from measurements of body specific gravity. During the control period fat was gained at the rate of $41 \mathrm{gm}$. per day-during administration of Compound A fat gain averaged $32 \mathrm{gm}$. per day. When Compound $\mathrm{F}$ was given, fat increased at a rate of $90 \mathrm{gm}$. per day during the first study and $64 \mathrm{gm}$. per day during the second, the latter value being obtained from data which included the control period between the two courses of Compound F.

Calculation of density of added tissue revealed a value of 1.026 during the control period and 1.040 during treatment with Compound A indicating a gain of all major body constituents. When Compound $\mathrm{F}$ was administered density of added tissue was 0.940 during the first study and 0.941 during the second. Available data indicate that these values approximate those of adipose tissue $(15,16) .^{5}$

\section{DISCUSSION}

The belief that adrenal hormones promote an increase in fatty tissue arose from clinical observation of the abnormal body configuration in Cushing's syndrome. Patients with this disorder usually manifest an apparent gain in fat, particularly distributed in the upper third of the body and frequently associated with wasting of the lower extremities. Studies of the relationship of adrenal hormones to body fat in lesser animals are so contradictory and difficult to interpret that complete review is redundant for the purpose of this discussion. Concise summaries of published work on the subject, such as those of Thorn and his associates (17), Ingle (18) and Engel and Scott (19) indicate that no clear-cut opinion regarding adrenal-fat relationships can be rendered. Studies

5 It should be noted that adipose tissue consists of fat, water and protein and, consequently, has a greater density than pure fat. 
TABLE I

Changes in body fat as estimated by different methods

\begin{tabular}{|c|c|c|c|c|c|}
\hline & $\bar{A}$ & $\overline{8}$ & C & $\bar{D}$ & $\bar{E}$ \\
\hline & $\begin{array}{l}\text { SPECIFIC } \\
\text { GRAVITY }\end{array}$ & $\begin{array}{l}0+T B W \\
\text { (SIRI) }\end{array}$ & $\begin{array}{l}\text { CORRECTION } \\
\text { OF } D=\frac{M}{M} \text { BY } \\
\text { SCN SPACE }\end{array}$ & $\begin{array}{l}\text { FROM FAT- } \\
\text { FREE BODY } \\
\text { MASS }\end{array}$ & $\begin{array}{l}\text { ANTIPYRINE } \\
\text { a NITROGEN } \\
\text { BALANCE }\end{array}$ \\
\hline$c_{1} \rightarrow c_{2}$ & +0.8 & +1.7 & +1.5 & +1.8 & +2.1 \\
\hline$C_{2} \longrightarrow F_{1}$ & +1.9 & +3.8 & +2.2 & +5.4 & +5.3 \\
\hline$F_{1} \longrightarrow C_{3}$ & +1.4 & -1.2 & +1.4 & -3.9 & -1.9 \\
\hline$C_{3} \longrightarrow F_{2}$ & +2.0 & +2.9 & +1.7 & +5.5 & +3.0 \\
\hline$C_{2} \longrightarrow F_{2}$ & +5.3 & +5.5 & +5.3 & +7.0 & +6.4 \\
\hline
\end{tabular}

conducted by Kendall (20) indicated a very significant increase in fat with Compounds $\mathrm{A}$ and $\mathrm{B}$, but Kochakian (21) found no lipogenic effect from purified Compound A.

Very few data are available on the relationships of corticoids and fat in humans. While there does appear to be a marked increase in fat in Cushing's syndrome it remains unknown whether this is a real gain or merely a redistribution. Neither is it known whether this "obesity" is the result of over-eating, the product of increased protein catabolism or tangible evidence of a direct hormonal effect. In fact we cannot even be sure that this local accumulation represents normal adipose tissue. Measurement of body fat by the specific gravity technique before and after the surgical correction of Cushing's syndrome is now underway in this laboratory. Preliminary observations indicate that correction of adrenal hyperfunction results in a significant decrease in body fat but also suggest that excessive body water is a major abnormality in Cushing's syndrome. Kinsell and his associates (22), from a study of diabetic patients, concluded that adrenal steroids accelerate the formation of carbohydrate from fat. Ziff, Simson, and Bunim (23) measured antipyrine, bromide and chloride spaces during adrenal stimulation in five patients with rheumatic disorders. In two cases weight gain exceeded the increase in antipyrine space to such degree as to indicate significant gain in body fat. Using the specific gravity method of fat estimation Doolan, Welham, and Kyle (3) studied the effects of ACTH and adrenal steroids on total body fat. ACTH ap-
TABLE II

Average gain in fat and density of tissue gained CONTROL Cpd.A Cpd.F(1) Cpd.F(2)

\begin{tabular}{l|c|c|c|c|}
$\begin{array}{l}\text { Density of } \\
\text { Tissue Gained }\end{array}$ & 1.026 & 1.040 & 0.940 & 0.941 \\
\cline { 2 - 5 } $\begin{array}{l}\text { Gain in Fat } \\
\text { (gm./day) }\end{array}$ & 41 & 32 & 90 & 64 \\
\hline
\end{tabular}

peared to induce loss of body fat without significant change in lean tissue suggesting that the excessive fat catabolism had spared protein. The administration of large doses of Compound $\mathrm{E}$ resulted in a marked increase in protein catabolism and an apparent relative sparing of body fat. During the administration of Compound $F$ there occurred a significant decrease in specific gravity, which, though partly the result of loss of lean tissue, also suggested an increase in fat.

The present study indicates quite definitely that Compound $\mathrm{A}$ has no measurable effect on total body fat. There did appear to be a significant and rather substantial gain in adipose tissue during treatment with Compound F. Because of the difficulty in explaining the mechanisms involved and in view of the limited application of these body compositional measurements in clinical investigation, it seems pertinent to re-evaluate the methodology employed before assuming that the gain in fat was real.

As pointed out by Keys and Brožek (11) the specific gravity of the fat free human body cannot be determined with precision. Furthermore, the fat prediction equation utilized in these studies is derived from measurement of small animals, whose proportional body composition and skeletal mass differs from the human subject. It is therefore obvious that a single determination of specific gravity, or even multiple determinations in a metabolically stable subject, cannot provide data which will portray the exact amount of body fat. In conducting serial determinations on a subject of changing fat content, however, a much higher degree of accuracy is possible. In our hands the summation of possible errors, including measurement of residual lung volume, accuracy of scale and reproducibility of replicate determinations indicate that loss or gain of fat must approach $1.5 \mathrm{~kg}$. to be significant. The gains in fat 
with Compound $\mathrm{F}$ observed here were well in excess of that figure.

Apparent gain in fat, as judged by lowering of specific gravity, could also result from addition of other material of low density, such as water, or loss of body constituents of high density, such as protein or minerals. In the study reported here it is obvious that there was insufficient loss of high density body constituents to account for more than a fraction of the specific gravity change. Consequently the existence of significant overhydration remains as the only factor which could lead to distortion of the data sufficient in degree to produce an artifactual gain in body fat. In the first study variation in total body water determinations was of sufficient magnitude to prohibit correction of minor hydration abnormality. However, the changes in weight, sodium excretion and water retention were nearly identical during treatment with Compound $\mathrm{A}$ and Compound $\mathrm{F}$ and only in the latter instance did there occur a significant change in specific gravity. In the second study more accurate measurement of antipyrine space and the addition of $\mathrm{D}_{2} \mathrm{O}$ and thiocyanate space measurements provided a clear indication that no significant water retention occurred. In fact, there appeared to be mild dehydration after the diuresis which followed cessation of treatment with Compound F. Such loss of water would tend to minimize the measured gains in body fat which occurred during therapy. Consequently all evidence indicates that the gain in fat was truly significant during treatment with Compound F.

The mechanisms responsible for the increase in body fat are completely obscure. Liponeogenesis from protein obviously did not occur and, as judged by oxygen consumption, there was no decrease in energy production during therapy. Thus we can only postulate some change in intermediary metabolism which permitted the addition of fat without appreciable change in the measured components of the metabolic pool. This supposition obviously lends itself to speculation regarding the hypothesis that some persons, at least under certain circumstances, can maintain their weight or even become obese on a remarkably small caloric intake. Studies of the type reported here should provide more exact data regarding gain or loss of body fat and permit a more objective approach to the problems of obesity.

\section{SUMMARY}

Serial determinations of body specific gravity were combined with balance study and measurement of body water compartments to determine the effect of Compounds $\mathrm{A}$ and $\mathrm{F}$ on body fat. The administration of Compound $A$ for 26 days had no demonstrable effect on body fat. The administration of Compound $\mathrm{F}$ for similar periods of time on three separate occasions was associated with a significant increase of total body fat. This gain in fat was not accompanied by evidence of either liponeogenesis from protein or decreased energy production.

\section{ACKNOWLEDGMENT}

We would like to express our appreciation for the assistance of the personnel of the Experimental Diving Unit, U. S. Naval Gun Factory in performing these studies. The advice of Drs. Albert Behnke and Will Siri has been invaluable in the conduct of this investigation.

\section{REFERENCES}

1. Behnke, A. R., Jr., Feen, B. G., and Welham, W. C., The specific gravity of healthy men. Body weight $\div$ volume as an index of obesity. J.A.M.A., 1942, 118, 495.

2. Kyle, L. H., Welham, W. C., Doolan, P. D., and Schaaf, M., Study of the extrathyroidal effects of thyroid-stimulating hormone. J. Clin. Endocrinol. \& Metab., 1954, 14, 1029.

3. Doolan, P. D., Welham, W. C., and Kyle, L. H., Studies on the effect of ACTH and certain adrenal steroids on total body fat. Metabolism, 1955, 4, 39.

4. Willmon, T. L., and Behnke, A. R., Residual lung volume determinations by the methods of helium substitution and volume expansion. Am. J. Physiol., 1948, 153, 138.

5. Rathbun, E. N., and Pace, N., Studies on body composition. I. The determination of total body fat by means of the body specific gravity. J. Biol. Chem., 1945, 158, 667.

6. Osserman, E. F., Pitts, G. C., Welham, W. C., and Behnke, A. R., In vivo measurement of body fat and body water in a group of normal men. $J$. Applied Physiol., 1950, 2, 633.

7. Brodie, B. B., Axelrod, J., Soberman, R., and Levy, B. B., The estimation of antipyrine in biological materials. J. Biol. Chem., 1949, 179, 25.

8. Broida, H. P., Morowitz, H. J., and Selgin, M., Optical spectroscopic determination of hydrogen isotopes in aqueous mixtures. J. Res. Nat. Bur. Stand., 1954, 52, 293.

9. Eder, H. A., Determination of thiocyanate space. Methods in Med. Research, 1951, 4, 48. 
10. Siri, W., Personal communication.

11. Keys, A., and Brožek, J., Body fat in adult man. Physiol. Rev., 1953, 33, 245.

12. McCance, R. A., and Widdowson, E. M., A method of breaking down the body weights of living persons into terms of extracellular fluid, cell mass and fat, and some applications of it to physiology and medicine. Proc. Roy. Soc., London, Series B, 1951, 138, 115.

13. Moore, F. D., Haley, H. B., Bering, E. A., Jr., Brooks, L., and Edelman, I. S., Further observations on total body water. II. Changes of body composition in disease. Surg., Gynec. \& Obst., 1952, 95, 155.

14. Clark, E. P., and Collip, J. B., A study of the Tisdall method for the determination of blood serum calcium with a suggested modification. J. Biol. Chem., 1925, 63, 461.

15. Behnke, A. R., Osserman, E. F., and Welham, W. C., Lean body mass. Its clinical significance and estimation from excess fat and total body water determinations. Arch. Int. Med., 1953, 91, 585.

16. Keys, A., Anderson, J. T., and Brožek, J., Weight gain from simple overeating. I. Character of the tissue gained. Metabolism, 1955, 4, 427.

17. Thorn, G. W., Jenkins, D., Laidlaw, J. C., Goetz, F. C., Dingman, J. F., Arons, W. L., Streeten,
D. H. P., and McCracken, B. H., Pharmacologic aspects of adrenocortical steroids and $\mathrm{ACTH}$ in man. (Continued.) New England J. Med., 1953, 248, 284.

18. Ingle, D. J., The biologic properties of cortisone: A review. J. Clin. Endocrinol., 1950, 10, 1312.

19. Engel, F. L., and Scott, J. L., The role of hormones in adipose tissue glycogen synthesis in the rat: The adrenal cortex. Endocrinology, 1951, 48, 56.

20. Kendall, E. C., Influence of the adrenals on carbohydrate metabolism. Conf., on Metabolic Aspects of Convalescence Including Bone and Wound Healing, 10, 1945, 81.

21. Kochakian, C. D., Adrenal cortical steroids. Conf. on Metabolic Aspects of Convalescence Including Bone and Wound Healing, 6, 1944, 13.

22. Kinsell, L. W., Michaels, G. D., Margen, S., Partridge, J. W., Boling, L., and Balch, H. E., The case for cortical steroid hormone acceleration of neoglucogenesis from fat in diabetic subjects. A summary of five years' investigative work. J. Clin. Endocrinol. \& Metab., 1954, 14, 161.

23. Ziff, M., Simson, J., and Bunim, J. J., Effect of ACTH on water distribution in man as measured by antipyrine, T 1824 and bromide. J. Clin. Invest., 1952, 31, 829 . 